\title{
A Learning Community of Beginning Teachers: A Systemic Intervention Based on Self-Determination Theory to Promote Autonomous Proactive Teachers
}

\author{
Haya Kaplan' ${ }^{(0)}$, Dafna Linker Govrin'1, Matty Mindlin² \\ ${ }^{1}$ Kaye Academic College of Education, Beer Sheva, Israel \\ ${ }^{2}$ Principal, Kohel Mekif Vav High School, Beer Sheva, Israel \\ Email: kaplanh@kaye.ac.il, govrind@gmail.com, mattymd2@gmial.com
}

How to cite this paper: Kaplan, H., Govrin, D. L., \& Mindlin, M. (2021). A Learning Community of Beginning Teachers: A Systemic Intervention Based on Self-Determination Theory to Promote Autonomous Proactive Teachers. Creative Education, 12, 2657-2686.

https://doi.org/10.4236/ce.2021.1211198

Received: September 26, 2021

Accepted: November 27, 2021

Published: November 30, 2021

Copyright $\odot 2021$ by author(s) and Scientific Research Publishing Inc. This work is licensed under the Creative Commons Attribution International License (CC BY 4.0).

http://creativecommons.org/licenses/by/4.0/

\begin{abstract}
The professional literature describes the complexity of the induction process and the importance of support systems for beginning teachers (BTs). The article discusses a unique self-determination theory (SDT)-based intervention program of learning communities (LC), called Multi-Players Induction Teams (MIT) that operate in schools. The program was developed and implemented as part of the international Proteach Program (Erasmus+ Project, European Union). It was led by a college of education in Israel, and has been researched as a three-year case study in one high school. Each year, 30 - 40 BTs, mentors, administrators, and policymakers participated in the program. The main tool employed in the study was a semi-structured interview. Additional tools included the workshop facilitators' end-of-year reports, meeting minutes and the participants' reflective journals. The findings show collaborative systemic work between the school and the policymakers in its locality. The absorption of BTs into the school contributed to improved school climate, and became part of school culture. Additionally, organizational structures promoting BT absorption were established at the school, and a need-supportive environment was established in both the MIT and the school. BTs and mentors express a sense of need satisfaction. The MIT affected the BTs' positioning at the school as influencing figures who led meaningful educational initiatives. The findings present a unique model of LCs that support teachers during their induction period. They can promote processes for integrating BTs into the education system as autonomous and proactive teachers by creating an environment that supports the psychological needs of BTs and experienced teachers alike.
\end{abstract}


Keywords

Beginning Teachers, Professional Learning Community, Psychological Needs, School Culture, Self-Determination Theory (SDT)

\section{Introduction}

Imagine ten interns and new teachers leading a teachers' lounge of 150 experienced high-school teachers, and demonstrating a new experiential learning method. This presents a different picture to that depicted in numerous studies reporting on the difficulties accompanying the absorption of beginning teachers (BTs) $^{1}$ into schools (De Neve \& Devos, 2017). However, as it transpires, it is possible to promote BTs to become proactive, involved, and lead meaningful processes at the school, and experienced teachers can learn from newcomers (Ulvik \& Langørgen, 2012). These aspects are discussed in the present article.

The professional literature describes the complexity of the induction process (Flores, 2017), and the importance of support systems for BTs (Kutsyuruba et al., 2017; Mcdossi \& Kaplan, 2019; Thomas et al., 2019).

The present article focuses on a new and unique support model, namely professional learning communities (PLC or LC) comprising interns, new teachers, mentors, school administrators, and policymakers called Multi-Players Induction Teams (MIT). The model was developed and implemented in Israel as part of the international Proteach Program (Erasmus+ Project, European Union), in collaboration with MOFET Institute, Ministry of Education, six academic colleges of education in Israel, Kaye, Beit Berl, Gordon, Sakhnin, Kibbutzim, and Talpiot, and four universities in Europe, University of Bucharest in Romania, University of Exeter in England, Tallin University in Estonia, and University of Salzburg in Austria. The model focuses on processes of growth and thriving, in contrast to problem-centered interventions (Collie \& Perry, 2019; Deci \& Vansteenkiste, 2004). The article discusses the self-determination theory (SDT)-based intervention program led by Kaye Academic College of Education (Ryan \& Deci, 2017), and demonstrates it through one school in which it was implemented. It describes the intervention model, and its effects on the school's BT absorption culture, and on the teachers' motivational world. The article begins with a description of the world of BTs, followed by the rationale for establishing MITs, and finally the intervention program itself.

\section{Theoretical Background}

\subsection{The World of BTs: From Dream to Survival}

The first years in teaching are considered one of most challenging periods in a teacher's career. Many BTs experience difficulties and concerns (Aarts et al., 2019; Schmidt et al., 2017). They come to teaching imbued with a sense of mis-

${ }^{1}$ The term "beginning teachers" refers to both "interns" and "new teachers" (first year after internship). All three terms will be used in this article. 
sion, but their dreams and ideals quickly turn into a daily struggle for survival (Kaplan, 2021a). Studies show that during this period, the new teachers' encounter with the school causes feelings of dissatisfaction and frustration (e.g., Pillen et al., 2013). These feelings stem from the gap between school reality and the professional knowledge, sense of competence in teaching, vision, and values with which the teachers have equipped themselves during their training at a college of education. New teachers encounter pedagogical, emotional, and social difficulties, and find it hard to adjust to the school's organizational culture (De Neve \& Devos, 2017).

Coping difficulties during this stage may result in teachers dropping out of the education system, especially quality teachers, a troubling phenomenon in many countries around the world (Boe et al., 2008; Sperling, 2015), and to impaired sense of wellbeing and professional functioning (Kaplan, 2021a).

\subsection{Beginning-Teacher Support Systems}

Support programs for BTs differ from one another in aspects such as target population, duration of the program, its components, and who is developing and leading the program, e.g., school or academic institution. In some cases, they are national or district initiative (Fresko \& Nasser-Abu Alhija, 2015; Howe, 2006; Sela \& Harel, 2018). The most prevalent support system is mentoring (Kutsyuruba et al., 2017).

The mentors support BTs in professional, emotional, organizational, and social aspects, provide feedback, and, in Israel, they also evaluate the BTs (Ford, 2017). Mentors' support was found to be associated with various positive outcomes among BTs, e.g., increased sense of professional efficacy, teacher enthusiasm, job satisfaction, and reduced emotional exhaustion (Burger et al., 2021; Richter et al., 2013), as well as improved teaching practices (Alegado \& Soe, 2021).

The literature presents additional programs that have been developed around the world, e.g., internet support from peers and mentors (Herrington et al., 2006), participating in group workshops (Lazovsky \& Zeiger, 2004), peer group mentoring with mentors and BTs (Pennanen et al., 2017), and others.

In light of the difficulties BTs experience, the Israel Ministry of Education, in collaboration with the academic colleges of education, established support frameworks during the induction period, including participation in an intern workshop, and in a new-teacher workshop a year after internship. Additionally, every BT is supported by a teacher-mentor. Studies show the contribution of such programs to BTs' emotional, professional, and organizational adjustment, and to improved teaching methods (Abu Ras, 2010; Fresko \& Nasser-Abu Alhija, 2015; Ingersoll \& Strong, 2011; Kaplan et al., 2016). In Israel, the BT dropout rate has declined over the years, following internship and participation in intern workshops (Central Bureau of Statistics, Israel, 2019).

Another support system focuses on professional learning communities (PLC) 
of new teachers, where teachers come together to promote their professional learning (Stoll et al., 2006). The roots of these learning communities trace back to early organizational learning theories, such as the work of Argyris and Schön (1978) and others.

PLCs are widely acknowledged frameworks for developing schools, and promoting teaching and learning (Antinluoma et al., 2021; Turner et al., 2018). These communities are based on trust and partnership, and facilitate a critical examination of teaching processes, as well as development of new knowledge, skills, and practices (Fresko \& Nasser-Abu Alhija, 2015). They lead to improved school efficiency, improved teaching practices, free expression of opinions, and participative decision making (Antinluoma et al., 2021), as well as improved student achievements (Lomos et al., 2011).

Most studies on PLCs of BTs use a school organizational lens or social network approach to examine BTs' experiences (e.g., Baker-Doyle, 2011; Frank et al., 2020; Qian et al., 2013). Moreover, an examination of the professional literature reveals that numerous studies on PLCs focus on the school as a community, and on the entire teaching staff, and to a lesser degree on communities of BTs, specifically communities combining BTs, mentors, administrators, and policymakers, that operate in the schools, as in the present study.

Studies on BTs generally focus on homogenous groups of BTs (e.g., Fresko \& Nasser-Abu Alhija, 2015), or communities outside the school, e.g., an online community of BTs (Herrington et al., 2006), or examine a specific aspect associated with the effect of the school community on BTs and on their teaching (Qian et al., 2013).

Furthermore, the research literature generally focuses on the prominent characteristics of PLCs, e.g., shared values and vision, teaching practices, reflective professional inquiry, collaboration, and promoting the learning of teachers or students. Very few studies on PLCs of teachers examined aspects of teachers' wellbeing, thriving, and motivation (Owen, 2016). Additionally, despite the extensive literature on the subject, it is still unclear how PLCs develop, and what are the change mechanisms that lead to professional and cultural improvement (Turner et al., 2018).

The present study describes a new SDT-based support model of school-based PLCs called Multi-Players Induction Teams, which was developed in Israel. SDT is a motivational theory that engages with the conditions that enable people to develop and thrive (Ryan \& Deci, 2017), and conditions that facilitate organizational change (Assor et al., 2018). These aspects are unique to the present study.

\subsection{Basic Premise: A Psychological Need-Supportive Environment}

The organizing conceptual framework of the Proteach model led by Kaye Induction Unit at Kaye Academic College of Education is SDT (Deci \& Ryan, 2000; Ryan \& Deci, 2017). According to SDT, people have three universal basic psychological needs: autonomy, relatedness and competence. Satisfaction of these 
needs, by means of support from the environment, contributes to optimal development, autonomous motivation, sense of wellbeing, quality engagement, and social adjustment, as well as processes of integrating and internalizing behaviors and values, namely identity construction processes (Kaplan, 2018, 2021b; Kaplan \& Assor, 2012; Assor et al., 2018; La Guardia, 2009; Reeve, 2006; Ryan \& Deci, 2017).

The need for relatedness is the individual's experience of having close, secure, and satisfying relationships with others in their social environment, and their desire to feel connected and to be part of a community. The need for competence is the experience of effectance and mastery, and the individual's desire to view themselves as capable of realizing intentions, plans, and objectives. The need for autonomy is the experience of self-determination, authentic self-expression, meaning, freedom of choice, and ownership in one's actions. On a deeper level, it is the individual's need to feel that their main actions are consistent with their basic needs, interests, inclinations, and values (Reeve \& Assor, 2011; Ryan \& Deci, 2017, 2020).

SDT emphasizes the quality of motivation, and therefore refers to different motivation types, which are classified according to the individual's level of self-determination, i.e., the degree to which they feel that their activity emerges from their authentic inner desires (Deci \& Ryan, 2000). Autonomous motivation is a state wherein the individual experiences a sense of choice, will, and self-determination, and acts from identification with the value or behavior (identified motivation), or from inner interest and profound satisfaction (intrinsic motivation). Controlled motivation is a state wherein the individual acts from a sense of coercion, pressure, hope for reward, and extrinsic commitment (extrinsic motivation), or from inner pressure, feelings of shame and guilt, and a desire to gain intrinsic or extrinsic appreciation (introjected motivation).

Behaviors stemming from extrinsic motivation can become self-determined through a process of internalization (Deci \& Ryan, 2000), an active process wherein beliefs, values, behaviors, and even demands that were previously driven by extrinsic motivation, become an integrative part of the self. The individual perceives the action as consistent with their identity, and as important in relation to other actions (integrative/autonomous motivation). Internalization is a major process in working with BTs, where emphasis is placed on promoting autonomous motivation for teaching.

The SDT approach is based on research (Ryan \& Deci, 2017, 2020), including studies conducted in Israel (e.g., Kaplan, 2018, 2021a, 2021b; Kaplan \& Madjar, 2017; Roth et al., 2007). Studies on in-service teachers focused on school environments as either supporting or frustrating teachers' needs (Ryan \& Deci, 2017), and on the association between teachers' need satisfaction and autonomous motivation, and a range of outcomes associated with teachers' functioning (Aelterman et al., 2016; Klassen et al., 2012; Van den Berghe et al., 2014). In various studies, autonomous motivation in teaching has been linked to a range of positive outcomes, e.g., sense of self-accomplishment (Roth et al., 2007), job sa- 
tisfaction and wellbeing (Nie et al., 2014), and to teachers' support for students' autonomy (Pelletier et al., 2002; Roth et al., 2007; Van den Berghe et al., 2014). Relatively few studies have focused on BTs, and their findings were similar (e.g., Fernet et al., 2016; Kaplan, 2021b; Kaplan et al., 2016).

\subsection{The Context of the Present Study: The Proteach Program and the MIT Model-Multi-Players Induction Teams}

Proteach is an international program and part of the European Union's Erasmus+ Project. Participants in the program include interns and new teachers, the school principal and other administrators (e.g., counselor, year coordinators), mentors, experienced teachers, and staff from the academic college of education. Policymakers are also involved, e.g., Ministry of Education superintendents, head of the local authority education department, and figures from the community. Together they form a unique PLC that has been named Multi-Players Induction Team, or MIT.

MITs are a new support model that began developing in Israel in recent years (Imanuel, 2019). They are founded on principles of community and collaboration, and are led collaboratively by the academic colleges of education, the Ministry of Education, MOFET Institute, local authorities, and the schools where the interns and new teachers are being absorbed. There are various MIT models for school and kindergarten BTs, including school-based MITs operating in one or several schools, and locality-based MITs.

The MIT model is grounded in a clinical approach that promotes BTs' experiences as close as possible to the ecological context in which they act (Imanuel, 2019). The MIT is a PLC that shares a vision and goals, and facilitates processes of professional identity construction through reflective dialogue. It enables teachers to learn about the school culture (norms, expectations, regularities), as well as the unique cultural context of the school's or the locality's population, and the MIT's content is adapted to these characteristics.

The primary aim of the MITs is to strengthen the voices of interns and new teachers. The term "voice" is a metaphor for the notion of autonomy. In this context, Reeve and Assor (Reeve \& Assor, 2011) defined the need for autonomy as the individual's striving to realize authentic values, abilities, goals, and interests, and to actively and exploratively form aims, outlooks, values, and new plans. Consequently, strengthening the voices of BTs means supporting their positioning at the school as autonomous individuals who are realizing the abilities, values, and ideals they bring to teaching, and continuing to construct their identity. The MIT community enables teachers to realize their autonomy through group guidance principles and methods, by promoting their proactiveness, and supporting the planning and implementation of educational and social initiatives.

\subsection{Group Guidance Principles and Methods in MITs}

The principles and methods developed in the project to provide autonomy sup- 
port, and sustain or promote autonomous motivation among BTs, are based on previous studies (e.g., Assor et al., 2002; Kaplan \& Assor, 2012; Reeve, 2006; Reeve \& Cheon, 2021; Ryan \& Deci, 2020). Numerous studies across multiple settings and domains show the benefits of psychological need support for human motivation, growth, and wellbeing (Ryan \& Deci, 2017, 2020). Numerous studies have been conducted among students, and focused on teacher behaviors (e.g., Assor et al., 2002; Reeve, 2006), counseling and psychotherapy (Ryan et al., 2011), and mentoring (Kaplan \& Israel, 2020).

Principles implemented in working with groups of BTs include:

\section{Autonomy Support}

- A flexible syllabus built in collaboration between school staff, interns, and new teachers, and the agenda, content, and processes in the group are jointly determined with the teachers.

- Activities include discussion of relevant authentic cases from the school, class, or the community.

- The dialogue in the group facilitates free expression of views and opinions, and an authentic emotional discourse.

- The group facilitator and school staff support the teachers' proactiveness and initiatives.

- The dialogue in the group facilitates identification of the teachers' fields of interest, strengths, and inner resources.

\section{Relatedness support}

- Emphasis on building the group as a safe place that enables safe dialogue.

- Emphasis on experiences that promote acquaintance and establish a community of BTs typified by empathy, consideration, caring, and mutual support.

- Reflective dialogue in the group, sharing experiences and feelings. Competence support

- The dialogue in the group promotes positive thinking, conceptualization of a difficulty or problem as a strength-based challenge.

- Teachers receive growth-promoting feedback (specific, non-judgmental).

- The group facilitator and school staff encourage the teachers to set optimal challenges (in teaching, initiatives).

- Emphasis on reducing social comparison, and on a non-competitive task structure.

\subsection{Prompting Proactive Involvement, and Support for Planning and Implementing Educational Initiatives}

One of the key principles in the program is the reinforcement of BTs' active and proactive engagement as a way of strengthening their voices. Thus, it promotes the planning and implementation of initiatives for the benefit of the school/class, or the community/locality.

According to SDT, leading initiatives is a means of supporting psychological needs, and fostering teachers' autonomous motivation (Ryan \& Deci, 2017, 2020). When teachers experience need satisfaction, taking initiative is more like- 
ly to be internalized and become a way of life, rather than dissipating once the project ends (Assor et al., 2018). Therefore, it is important for the teachers' needs to be supported by the group facilitator, the principal, and the experienced teachers during the process of coming up with an idea, planning the initiative, and implementing it. The initiative should be based on the new teacher's fields of interest, talents, ideals, values, and strengths, rather than imposed on them, and should be relevant to their work, while also facilitating development of new fields of interest (autonomy support). The initiative enables optimal challenges to be set, new skills and abilities to be learned, growth-promoting feedback, and an experience of success (competence support). The process strengthens acquaintance and collaboration between experienced teachers and BTs (relatedness support).

In the process of choosing an initiative, the teachers also examine the school's needs, values, and characteristics, and attempt to create balance between them and their fields of interest. The process is accompanied by a reflective and explorative dialogue (Kaplan \& Assor, 2012; Kaplan et al., 2016) that focuses on aims, values, ideals, and dreams concerning education and teaching, identifying gaps, and a discussion on how the initiative can reduce these gaps.

According to Fullan (2007), teachers can be effective agents of change. Teachers possess inside knowledge concerning the students and their needs, the curricula, and the school, which can bring about the kind of improvement that they and their colleagues need (Turner et al., 2018). Encouraging new teachers to promote educational initiatives is based on belief in their abilities and the inner resources they bring to teaching. It is a way of promoting teachers as agents of change in the school, even though they are just starting their career as teachers.

\section{The Present Study}

The present study discusses an intervention program that operated in a six-year high school located in a major city in Israel's south. Over the years, the program was accompanied by a qualitative evaluation study employing an instrumental case study research design (Yossifon, 2016).

The intervention included operating a workshop for the MIT community (interns, new teachers), a two-year training course for teacher-mentors, joint meetings of interns and new teachers and their mentors, and joint meetings with the school administrative and teaching staff. Systemic work was also carried out, and support mechanisms for the absorption of BTs were established at the school.

This article presents findings associated with the effects of the MIT on school culture, BTs' and mentors' experiences of psychological need support or suppression, BTs integration into the school, and the contribution of the mentoring they received. The research questions were: How was the systemic work at the school expressed? What is the MIT's contribution to the BTs' and mentors' experiences of need satisfaction (competence, relatedness, autonomy)? What is the 
MIT's contribution to the school?

\section{Method}

\subsection{Participants}

The participants were interns, new teachers, mentors, administrative staff, policymakers, and the MIT staff (group facilitator, absorption coordinator).

The BTs and mentors taught a variety of subjects at the school, in the sciences and humanities, languages, and so on. In most cases, the mentors mentored BTs from the same discipline. The administrators participating in the study were the school principal, the vice principal, the school counselor (who was the absorption coordinator), and the grade coordinators. Most of the interns went on to become new teachers at the school, and continued participating in the MIT in their second year as well.

The study was conducted in a high school in Israel, where secondary education is from $7^{\text {th }}$ to $12^{\text {th }}$ grade. The school comprises a junior high school $\left(7^{\text {th }}-9^{\text {th }}\right.$ grade) and senior high school $\left(10^{\text {th }}-12^{\text {th }}\right.$ grade $)$. The studied school population comprises about 1900 students and 200 teachers, and is typified by its cultural and socioeconomic diversity.

Table 1 shows the composition of interns, new teachers, and mentors at the school during the three-year intervention.

\subsection{Research Tools}

The main tool was a semi-structured interview with interns, new teachers, mentors, administrators, and the head of the local authority education department. Over three years, some of the interviewees were interviewed more than once, e.g., once as interns, and once as new teachers. The school principal was interviewed several times. A year after the project ended, additional interviews were held with the school principal, the absorption coordinator, an intern, and a mentor.

The interview with the BTs began with a broad question: "Tell your story as a beginning teacher this year". Later, the teachers were asked open questions about their feelings as BTs, their absorption at the school, the mentoring they received, educational initiatives, and the workshop. The interview with the teacher-mentors also began with a broad question: "What does being a teacher-mentor

Table 1. Composition of participants at the school during the three-year intervention.

\begin{tabular}{|c|c|c|}
\hline Year 1 & Year 2 & Year 3 \\
\hline $\begin{array}{l}13 \text { interns and } 4 \text { new } \\
\text { teachers ( } 17 \text { BTs), } 15 \\
\text { women and } 2 \text { men. }\end{array}$ & $\begin{array}{l}7 \text { interns and } 14 \text { new teachers } \\
(21 \text { BTs), } 18 \text { women and } 3 \\
\text { men. }\end{array}$ & $\begin{array}{l}11 \text { interns and } 6 \text { new teachers } \\
\text { (17 BTs), } 15 \text { women and } 2 \\
\text { men. }\end{array}$ \\
\hline $\begin{array}{l}\text { Every teacher was } \\
\text { supported by a mentor. }\end{array}$ & $\begin{array}{l}\text { Mentor course for } 20 \\
\text { teacher-mentors who } \\
\text { mentored the BTs. }\end{array}$ & $\begin{array}{l}\text { Continuation of mentor } \\
\text { course; Every teacher was } \\
\text { supported by a mentor. }\end{array}$ \\
\hline
\end{tabular}


mean for you?" Later, they were asked open questions about the choice to become a mentor, and about the mentoring and absorption of BTs at the school, the course, and the BTs' initiatives.

Additional research tools include the workshop facilitator's end-of-year reports. These reports included an analysis of the process that took place at the school during the year, a description of the main activities, the degree to which goals were achieved, quotes from the teachers' feedback, and more. Another tool was the meeting minutes. Additionally, the participants kept reflective journals, in which they wrote about their thoughts, feelings, and experiences in the MIT meetings, at the school, in teaching, their contact with various figures, difficulties, challenges they faced, and more.

Table 2 shows the interviews conducted at the school during the three-year intervention.

\subsection{Procedure and Ethics}

The data were collected by evaluators who were not involved in the program. The data analysis and summary were conducted by an evaluation coordinator. The teachers were informed of the evaluation processes that would be accompanying the program, gave their consent, and signed informed consent forms. The interview transcripts were not passed on to the school administration or the facilitators. The positions of policymakers who were interviewed for the study are not stated in the article in order to protect their identity.

\subsection{Data Analysis}

The interviews underwent thematic content analysis (Kacen \& Krumer-Nevo, 2010; Shkedi, 2003), by years and by membership group. Findings obtained from the other research tools were incorporated into the themes that emerged. For example, information about topics associated with systemic work was supported by the program's protocols.

Analysis of the interviews comprised a number of stages (Creswell \& Poth, 2018). In the first stage, a holistic reading of each interview was carried out. In the second stage, the information was classified into units of meaning according to themes, and initial categories were created. In the third stage mapping analysis was carried out in order to formulate the full array of categories. The data analysis methodology partially focused on criteria (Shkedi, 2014): some themes stemmed from SDT, e.g., feelings of need satisfaction. A directed approach to

Table 2. Interviews conducted during the three-year intervention.

\begin{tabular}{|c|c|c|c|}
\hline Year 1 & Year 2 & Year 3 & $\begin{array}{l}\text { Year } 4 \text { (after the end of } \\
\text { the project) }\end{array}$ \\
\hline $\begin{array}{l}8 \text { interns and new } \\
\text { teachers; } 3 \\
\text { administrators }\end{array}$ & $\begin{array}{l}8 \text { interns and new } \\
\text { teachers; } 5 \text { mentors; } 4 \\
\text { administrators }\end{array}$ & $\begin{array}{l}7 \text { interns and new } \\
\text { teachers; } 3 \\
\text { administrators }\end{array}$ & $\begin{array}{l}2 \text { administrators; } 1 \\
\text { beginning teacher and } 1 \\
\text { mentor-mentee pair }\end{array}$ \\
\hline
\end{tabular}


content analysis is widely used to probe qualitative content (Hsieh \& Shannon, 2005).

To examine the study's reliability, at the beginning of the process the research team jointly analyzed five interviews. Disagreement regarding the themes that were extracted, or suitable quotations for each theme, were discussed until agreement was reached. This process facilitated an examination of the degree of inter-researcher reliability, and formulation of the analysis guidelines (e.g., how to classify a quote that is suitable for more than one theme).

\section{Findings}

The Findings section comprises six themes: Theme 1 focuses on systemic work in collaboration with policymakers; Theme 2 describes the effects of the MIT on school culture, and focuses on outlooks and values, as well as structural aspects associated with the BTs' optimal absorption; Theme 3 refers to experiences of psychological need satisfaction in the MIT community; Theme 4 describes experiences of need satisfaction in relation to the school and teaching; Theme 5 engages with the BTs' initiatives as a means of supporting their psychological needs; and Theme 6 focuses on mentoring supporting the psychological needs of BTs and experienced teachers.

\section{Theme 1: Systemic work in collaboration with policymakers}

The findings indicate that work at the school was characterized by systemic work in collaboration between the school administration, Ministry of Education superintendents, and the head of the local authority education department. The policymakers acknowledged the MIT's contribution to the quality of the teachers' teaching, and to the school. A key educational figure in the school's locality said:

The MIT has importance in aspects of professionalism, support, connection with the teacher him/herself, the institution, and the community [...] The program meshes with the worldview and values leading education in the city $[\ldots]$ We're transforming the new teachers into agents of change in the schools. The MIT enables a community to be formed that provides a sense of belonging and relevance. The dialogue between academia, teachers, and decision makers is welcome. This is a successful intervention that should be systematically passed on to other places. (Interview, Year 3)

The importance of involving various elements in improving the absorption processes was expressed in a meeting of the school management committee attended by representatives of the Ministry of Education, the local authority, and the school administration.

The MIT was presented at a management committee meeting, which was also attended by the school's superintendent, and the head of the city's education department. The principal began by giving some background on the MIT, then the counselor presented the subject of mentoring and its 
contribution, and then a mentor and an intern presented their mentoring relationship, which expressed a response to their psychological needs. Then, two interns presented their initiative, which they conceived together during their internship. (Meeting minutes, management committee, Year 2)

The MIT became known in the city and the Ministry of Education, as described by the school principal:

We describe the program at every opportunity when the school's work program is introduced. The municipality and the Ministry of Education are familiar with the program. It's important to me to present the MIT, maybe because it's process work that's become part of the school culture [...] On many occasions the superintendent has sent people to us to see the model we've developed. (Interview, school principal, Year 3)

\section{Theme 2: Effects of the MIT on school culture}

The findings show that absorption of BTs has become part of school culture. This is evidenced in the connection between absorption and the school's basic premises and values, links between the college's and the school's outlooks, establishment of a common language, and in the new regularities that have been incorporated into the school.

The findings indicate a connection between the aims of the MIT and the school's vision, which places emphasis on supporting the teachers' and students' autonomy. The school administration recognizes the benefits of the MIT, and allocates time and human resources to it. The teachers report on support from the principal, mentors, administrators, and experienced teachers. The MIT contributed to the creation of an optimal school climate. The school was awarded a prize for absorption from the Ministry of Education, which attests to the MIT's visibility and contribution to the school and the BTs.

The benefits of the MIT and its effect on school climate are described by the principal:

There's no doubt that turning the school into an MIT, where the teacher-mentors are teachers from the school, is a huge advantage. The partnership and the MIT model promoted the way new teachers are absorbed into the school, and quite naturally, this affects the climate in the entire school. (Interview, Year 3)

The principal emphasized the connection between the school's vision and the MIT:

I see the MIT as a means for making the school's vision and its aims accessible to the BTs, as well as the mentors. The first years in teaching are difficult. Engaging with the school's ideology already at this stage facilitates more optimal absorption. An intern who's preoccupied with survival, that has no connection to the school's vision and aims, can't develop a channel of personal aims with an optimistic eye to the future. (Interview, Year 4) 
The MIT projected onto relationships between the teachers, and onto the school climate, as described by the principal:

The school is typified by considerable differences between the teachers. The MIT facilitated social interactions between the different groups, brought experienced and new teachers closer to each other, and strengthened the teachers' sense of belonging. The MIT connects with the school's vision, which places emphasis on promoting the teachers' autonomy, while strengthening their competence in teaching. (Interview, Year 3)

A new teacher attests to an absorption culture at the school, and describes how he was welcomed at the school from his very first day there:

The moment I entered the school, I was introduced to all the figures and administrators I would come into contact with during the year. Since my first day at the school, and to this day, I feel I've always got someone I can turn to, there's support and help from everyone around me. (Interview, Year 2)

The absorption coordinator refers to the new language that has been established, the uniform messages conveyed to the teachers, and the MIT's effect on the teachers' sense of belonging:

The fact that the beginning-teacher workshop is held at the school is a key factor in improving the absorption processes. The school staff s accessibility strengthened the connections between the college and the school, and promoted one language and uniform messages. The MIT strengthened the teacher's sense of belonging to the school. (Interview, Year 2)

The systemic work was typified by establishing mechanisms, regularities, and events associated with optimal absorption, indicating that the absorption of BTs is a central subject at the school. An absorption coordinator was appointed (the school counselor), an absorption team was established, and a mentor training course was held at the school that emphasized need-supportive mentoring. Mentoring regularities were established: assigning mentors at the beginning of the year, and regular mentor-BT meetings throughout the year. Joint meetings between administrative and teaching staff were held at the school, where the absorption of new teachers was discussed (e.g., an experiential learning session led by new teachers, presentation of initiatives, and more). Additionally, an annual program for the absorption of new teachers was formulated, which details the rationale, aims, mechanisms, and activities throughout the year, and a website on absorption matters was built (information based on program protocols and documents).

Some of the mechanisms focused on collaborations between the school and the college, which led to continual improvement in absorption culture, in the nature of the collaborations, and in their significance. This aspect is described by the principal: 
The workshop facilitator and the absorption coordinator worked closely together over the years. Their work was typified by understanding, mutual respect, and collaboration. This way of working brings the MIT even closer to the school, and helps to provide responses to school needs. (Interview, Year 3)

The absorption coordinator relates that mentoring has become part of school culture:

Assigning teachers to mentors at the beginning of the year, and generally, the importance of consistent mentoring at regular times, is something that's part of the school culture. Our principal is in the picture, and involved in the considerations concerning the program. (Interview, Year 4)

\section{Theme 3: Experiences of need satisfaction in the MIT community}

The workshop-oriented process in the MIT is perceived as need-supportive of the relationships between the teachers themselves, as well as between the teachers and the group facilitator. The interviewees note the sense of belonging they developed towards the other group participants, and describe a need-supportive guidance process: attentiveness, supporting relevance, emotional, social, and professional support, and encouraging choice, collaborations and mutual learning, involvement in decision making in the group, and exploration processes. This support leads to a sense of need satisfaction, and satisfaction in general. Expressions of identity construction processes are also evident.

The participants experienced an autonomy-supportive process. The workshop facilitator describes a variety of ways in which the need for autonomy is supported:

Sense of autonomy was supported in different ways: every meeting began with an activity that was planned and led by one of the teachers, and a team was appointed to represent the group in a joint discussion with the group facilitator on selected content. The group's "voice" was heard regarding the choice of different topics, such as contending with class management problems, and giving room for a problem-solving model proposed by an intern, teachers leading initiatives, holding a social gathering outside the school, which was led by two interns, and more. (End-of-year report, workshop facilitator, Year 2)

At the end of Year 2, the MIT participants attest to an increased sense of autonomy and competence, in personal and professional aspects alike:

The workshop was very powerful for me, I understood a great deal about myself as a teacher, I realized I sometimes work on autopilot, without emotion, I realized I need to listen more, and I learned to listen to myself more. (Reflective journal, intern)

The group facilitator describes how she worked with the group on the need for relatedness: 
The teachers' need for relatedness was evident. The processes in the group built up the sense of confidence and trust. We delved into acquaintance processes, and built up the group. The meetings with the school administration, and the initiatives the teachers led, supported their sense of belonging to the school. (Interview, Year 3)

The principal views the MIT as a place of safety and friendship, i.e., supporting relatedness:

The sense of safety, the social cohesion, these are good conditions for growth for the new teachers at the school, in terms of being seen and heard. (Interview, Year 3)

One intern sees the school and the MIT as an extension of her home, and expresses her sense of belonging:

The fact that the workshop is held here is another layer of my success. Because when it's at the school it's easier to be connected [...] Sometimes I just stay here, catch up on things. It's like a home for me. (Interview, Year 2)

Participants attest to close, personal acquaintance with members of the group and additional staff members during activities in the workshop:

In the meeting today there was a feeling of containing. Everyone who wanted to, had an opportunity to speak and share, and the things that were brought in were interesting. I liked the personal conversations that took place in the meetings. (Interview, new teacher, Year 3)

The workshop supported sense of competence:

The MIT workshop gave me a range of solutions to a lot of difficulties that popped up along the way. Every Tuesday afternoon I had an opportunity to disconnect from all the things preoccupying me, open up my little Pandora's box, and contend with things that get in the way of fulfilling my role as a teacher. (Interview, intern, Year 3)

As part of the MIT's outlook and principles, the syllabus was dynamic and flexible, and reflected the workshop participants' involvement. Many of the meetings resulted from the participants' requests, e.g., holding a meeting in a café that was planned by two teachers, and all the participants reported that it was meaningful for them. A new teacher related:

One particular meeting was held at my initiative. A decision was made to hold a meeting off school grounds. The planning and organization were done by my group, and it was a fun, social, group-building meeting, and a great success. (Interview, Year 2)

Autonomy-supportive processes encouraged the participants to examine themselves in an exploration process, and indicate identity construction, as expressed in the participants' reflective journals during Year 2. 
In the second part we discussed with experienced teachers the values we incorporate into teaching. It was interesting to discover my own answers to these questions, since this is something I haven't necessarily thought about. Also, hearing personal views and experiences of people with extensive experience in teaching definitely shed a different, encouraging light on the experiences I'm contending with. (New teacher)

Personally, I felt that the workshop in which we used photography techniques made it possible for me to find a place to express my feelings, which wasn't always easy, and to find a balance between what's in the past and what can still continue. (New teacher)

The processes of identity construction projected onto the participants' teaching and their desire to remain at the school. Sense of autonomy enables the teachers to face the challenges of teaching, as expressed by interns in Year 3 (reflective journals):

Most important of all are the main insights I gained from the workshop when the facilitator referred to emotional activity [...] I noticed differences of opinion in the group regarding the question: "How do I take this activity for myself as a teacher?" I was amazed to see the full participation of everyone present $[\ldots]$ I learned and understood that as a teacher I first have to get to know the students.

\section{Theme 4: Sense of need satisfaction in relation to the school and teaching}

Following their internship year, the new teachers describe intensive, ongoing activity, accompanied by a sense of overload and extreme changes in emotional experience, which are influenced by events in the classroom. A new teacher used "marathon" as a metaphor to describe the experience of overload and being in a constant race:

Maybe a rollercoaster, maybe a marathon, the racing, that is, I felt like I didn't have a life. Everything revolves around the role of homeroom teacher: get through the material, manage to update, be prepared for lessons, be with the students, solve discipline problems, keep in touch with parents. It's a train and you don't know when you arrive, when it ends, where to? (Interview, Year 1)

At the same time, it appears that the school provided the BTs with an environment that enables them to experience the process, even if it is difficult and challenging, as a growth-promoting process. Sense of need satisfaction was experienced through contact with administrators and experienced teachers. The main need referred to in greater detail by the participants is the need for relatedness. They use terms such as "fraternity", "joy of togetherness", and "peer group". For example, new teachers write in their reflective journals in Year 2:

Thanks to the workshop I got to know teachers from different disciplines. As new teachers, when we meet at school, we always talk about our expe- 
riences. The feeling of a "fraternity of beginning teachers" is very comforting, we're all undergoing the same experiences. The MIT helps me form connections with the staff, and my sense of relatedness to the students is growing.

The absorption coordinator refers to the teachers' sense of belonging from her perspective:

The chances of someone extending a warm welcome to a teacher in the morning was next to zero, I don't think anyone took the time. Following the MIT, I see their joy of togetherness in the group. (Interview, Year 2)

An environment characterized by support was established at the school. The teachers feel they are in a safe place where they can sound their voice:

"Incubator" is undoubtedly the right word for the workshop. From the very beginning I felt comfortable speaking openly about things that bother me. For me, the incubator created a support group. (Interview, intern, Year 2)

Satisfaction of the teachers' need for competence is evidenced in their participation in a day of special activities at the school, in which they mentored experienced teachers on pedagogical innovation. The absorption coordinator described this process:

Teachers in their second year in the MIT participated as instructors of experienced teachers, and presented ICT pedagogy. Growth of the new teachers' competence and autonomy is evident in this event since it is they who chose to do it. It wasn't compulsory or part of their job. (Interview, Year 2)

Sense of autonomy also gained significant expression in processes associated with choosing and executing initiatives, as demonstrated in the next theme.

Theme 5: The BT's initiatives as a means of supporting psychological needs

Over the years, the BTs initiated and led diverse social and educational projects. In Year 1, they initiated a website on absorption. From Year 2 onward, they initiated more than ten initiatives, for example: a sign language course for teachers, designing a school shirt, "I want to share my historical personal story with you" - building a bank of experienced teachers' personal stories that intersect with Israel's history, developing a community garden, and more. The initiatives were presented to the school's administration and teachers, and were adopted by additional teachers (information based on meeting minutes). The initiatives supported the BTs' psychological needs, as evidenced by their descriptions:

I really enjoyed promoting this initiative. It's something that's in my blood. I love everything associated with sign language, and really enjoy sharing my knowledge with others. (Interview, intern, Year 2)

The meeting with the school's extended administrative staff, where I pre- 
sented my initiative, was meaningful. I really enjoyed initiating something during the year that's so meaningful for me, "Pedagogical Islands" is an amazing project that was created in the MIT, and led many students towards collaborative learning and making new friends, and significant improvement in their scholastic achievements. (Interview, intern, Year 2)

The participants attest that the initiatives strengthened their sense of relatedness and competence, as well as their positioning at the school:

I feel that being a teacher who initiates strengthens our sense of belonging, sense of competence (which builds up with the experiences we have and the challenges we face when we begin teaching), and it also strengthens our standing alongside the experienced teachers at the school. (Interview, new teacher, Year 3)

An intern describes the process, which she experienced as a process of growth:

For me, the process was like a baby who's learning to walk, discovering his first steps, a bit wobbly and unsure at first, at times hesitant, holding onto objects around him, then letting go, and finally walking on his own. $\mathrm{He}$ might fall, bump into things, cry, but in the end he'll succeed on his own and by himself. (Interview, Year 2)

An intern who developed a unique initiative for dialogue between herself and her students, expresses the experience of need satisfaction. She chose an initiative that suited her educational outlook, she felt that her voice was being heard (sense of autonomy), the success of the initiative strengthened her sense of competence, and its dissemination at the school strengthened her connection with the entire staff:

My choice really suits a humanistic educational approach, and emphasizes dialogue-based human connections [...] The possibility to promote subjects that are important to me, and the fact that the initiative exceeded expectations, strengthened my sense of competence. Also, the school encouraged me to share the initiative and disseminate it to the other classes. The support strengthened my sense of relatedness, and made me feel that my voice is being heard at the school. (Interview, Year 2)

The absorption coordinator presents her outlook regarding the BTs' initiatives: The initiatives empower the teachers, and enable them to express their uniqueness. The main idea is to give them a platform for autonomous action that will elevate their sense of competence and their place at the school [...] The initiatives were authentic, and enabled the new teachers to take centerstage as leaders. (Interview, Year 3)

Theme 6: Mentoring supporting the needs of BTs and experienced teachers alike

The findings indicate that mentoring is a significant element of support. The 
interns and new teachers express a sense of need satisfaction The mentors report on the contribution of mentoring to their own professional development. The teachers use various metaphors to describe the mentor's role: attentive ear, mother, guide, shoulder to lean on, compass, big brother. Mentoring helps them professionally, e.g., knowledge enrichment, support for teaching skills, contending with classroom management, providing feedback, and acquaintance with the school's structure and routines (competence support). The mentors are available, they express concern, care, and provide emotional support (relatedness support).

Being supported by my mentor is the main thing that helped my absorption. She showed me the place, explained, and mediated between me and the staff. (Interview, intern, Year 2)

A teacher-mentor supports a new teacher professionally and socially, and provides a response to the new teacher's everyday needs. The mentor also helps the intern to assimilate the school's educational outlook, and to clarify work procedures at the school. (Interview, mentor, Year 2)

One intern describes her mentor as a mother, and expresses her sense of relatedness with reference to mentoring:

My mentor is like a mother, which is amazing, great, comforting, full of hope, lots of confidence [...] It gives you a lot of strength, the first year is considered the most difficult, so it's amazing. (Interview, Year 1)

The process of competence support is carried out concurrently with relatedness support and forming profound connections:

Whenever I have a problem, she's there ... she's a guide [...] I can always turn to her, ask about lesson plans, how to improve, how to fix [...] When I'm having a hard time, I cry and go to her, or when I'm happy I share it with her. I think she also puts a lot into it. She wants me to succeed. She gives me tips that aren't only connected to the job itself, but how things are done here: how to deal with teachers, the staff (Interview, intern, Year 2)

The mentoring is also characterized by autonomy support: providing choice, authentic dialogue, free expression of ideas and feelings that enable BTs to lead themselves autonomously, as expressed by mentors and interns alike:

My mentor gives me a platform to show and express myself, she enables and creates opportunities for me to excel and express my ideas. A deep connection was formed between us, which is expressed beyond our formal meetings. (Interview, intern, Year 3)

He doesn't press, he doesn't suffocate me. When I need to, I know I can turn to him. He's really supportive, he gives me independence. And he trusts me. "Build whatever tests you want, whichever way you deem fit". (Interview, intern, Year 3) 
The reciprocal relationship between mentors and mentees is also expressed in the mentors' sense of need satisfaction, and their sense of mission. This attests to autonomous motivation for mentoring. At the end of the year in the mentor course, the mentors wrote: "It was meaningful, I enjoyed it, and I want the teacher I mentored to succeed"; "I was meaningful in the teacher's life, she succeeded - and that's a source of great satisfaction in my view". (Reflective journal, Year 3)

The mentors express autonomous motivation for mentoring:

From personal experience, I really believe in teacher-mentors mentoring interns. I felt it was a genuine mission, and performed my role with love and from a genuine desire to pave the way to success for the intern. I believed in my mentee's abilities and skills to be a respected teacher, and the relationship between us was one of trust and mutual respect. (Interview, Year 3)

The contribution of mentoring to the school was expressed by the absorption coordinator, who referred to enlisting the teachers for the role of mentor from autonomous motivation, not coercion.

The mentor course responded to the school's needs. It facilitated the establishment of a group of teachers who recognize the importance of mentoring, and come to it from intrinsic motivation for the process. In previous years, enlisting teachers for mentoring roles was initiated by the school administration, it was a role they were required to fill. In contrast, in the current course, it was the teachers who chose to participate. (Interview, Year 4)

\section{Discussion}

The findings indicate systemic work in collaboration between the school administration, Ministry of Education superintendent, head of the local authority's education department, and additional administrators. In the school's locality, the program was positioned as a meaningful one that contributes to quality of teaching.

The absorption of BTs into the school has become part of school culture. The incorporation of absorption into the school's existing culture is evident in the link found between the school's basic premises and values, and the MIT, in the new common language that was established, in the congruence between the college and the theoretical outlook it led (SDT), and the school's outlook, which places teacher and student autonomy at the center. Additionally, organizational structures promoting BT absorption were established at the school. It is evident that the MIT affected reciprocal relationships in the organization, and contributed to improved school climate.

The environment in the BT and mentor workshops and the school supported the teachers' psychological needs. BTs and mentors express a sense of need satisfaction and positive emotions.

An experience of optimal absorption is evident among the BTs, and of their 
positioning as meaningful and influencing figures at the school. The findings indicate that the social and educational projects initiated by the MIT participants contributed to the school and to the teachers themselves, and some of these initiatives were assimilated into school routines. Processes of professional development and identity construction are evident.

\subsection{The Effect of the MIT on School Climate and Culture}

The findings reinforce current knowledge concerning PLCs, and the connection between them and school climate and culture. Climate and culture are distinct concepts (Antinluoma et al., 2021). Organizational culture refers to shared vision and values, norms, collaboration, reflective dialogue, emphasis on teacher and student learning, and social interaction within the organization. Culture creates coherence, regularities, and behavior patterns, and provides a sense of identity (Oplatka, 2015; Teasly, 2017). School climate refers to people's individual experiences, teachers, students, administrators, their feelings, and their attitudes towards the organization. PLCs have a beneficial impact on the creation of a school-wide culture (Antinluoma et al., 2021; Turner et al., 2018). A positive climate and a positive school culture can promote the school's development as a PLC. Some even view school culture as a central characteristic of a PLC (Antinluoma et al., 2021).

The present study did not examine the organizational culture at the school prior to the start of the program. However, it appears that the school culture within which the MIT community operated enabled its establishment, and over the years congruence was found between the theoretical outlook led by the college (SDT) and the school's outlook. The PLC became part of the existing school culture, but also influenced it. Thus, BT absorption became part of the school's vision and values, new mechanisms and regularities were introduced (mentoring work practices, annual absorption model), new roles were created (leading team, absorption coordinator), and relationships of trust were established, as well as different ways of supporting BTs. The effect on the organizational culture was also evident in the new language that was created at the school, which was influenced by the SDT approach. Concepts such as relatedness, competence, autonomy, and autonomous motivation have become part of everyday discourse at the school.

The program's contribution to school climate is evident in the sense of need satisfaction expressed by the BTs, both with reference to the MIT community, and the school. These experiences are essentially emotional, and they projected onto the teachers' feelings towards the school, and their experience of the induction period. School climate was evident in the relationships between staff members, and especially between experienced and new teachers, and in the contact with the principal and other administrators. The teachers express a sense of relatedness and identification with the school, they feel safe, express their personal abilities and resources, and they develop professionally. All this is possible due to 
the school culture of supporting psychological needs, which projects onto a positive school climate, the teachers' feelings, and their experiences at the school.

\subsection{The Importance of a Need-Supportive Environment}

The findings indicate that a psychological need-supportive environment promotes optimal integration of new teachers into the school and the teaching profession. These findings are consistent with those of previous studies that examined connections between teachers' psychological need support and a range of positive outcomes. Thus, for example, connections were found between need support and experiences of need satisfaction, and autonomous motivation for teaching, self-actualization, and engagement (Eyal \& Roth, 2011; Kaplan et al., 2016). The teachers' autonomous motivation was found to be associated with outcomes such as greater engagement in their work (In de Wal et al., 2014), sense of self-actualization and reduced sense of burnout (Fernet et al., 2008), and students' autonomy support (Pelletier et al., 2002; Roth et al., 2007).

Despite the extensive data in the literature about the difficulties experienced by BTs, there is relatively little information about the motivational processes characterizing new teachers in an SDT framework (De Neve \& Devos, 2017; Fernet et al., 2016). For example, Fernet et al. (2016) found that workload predicts controlled motivation, which in turn predicts emotional burnout. Additionally, receiving positive evaluations and opportunities to make decisions are associated with autonomous motivation, which in turn predicts commitment to work, positive relationships with students, and reduced emotional burnout. Other studies focused on the experience of need satisfaction among preservice teachers. For example, Kaplan \& Madjar (2017) found that need support contributed positively to need satisfaction and autonomous motivation among Jewish and Bedouin preservice teachers. In turn, autonomous motivation contributed positively to sense of self-actualization and engagement in learning.

The above findings were obtained in quantitative studies. The present study is unique since it focuses on an intervention program accompanied by qualitative research. Together, the findings indicate the importance of a need-supportive environment for teachers in general, and BTs in particular.

Incorporating the field of motivation in general, and SDT in particular, in the intervention, and evidence of the applicability of this theory in the accompanying study, indicate a unique component of PLCs, as shown in the present article. The present study proposes a new, additional characteristic, namely the participants' experience of need satisfaction and ways to support them. Examination of the research literature reveals that there are no studies on PLCs and SDT, and only a handful that address student LCs (e.g., Beachboard et al., 2011). The present intervention and study fill this gap in the research.

\subsection{The Importance of Support Systems for New Teachers}

The findings are consistent with those of other studies demonstrating the posi- 
tive effects of the mentoring process (Ingersoll \& Strong, 2011; Richter et al., 2013). Studies show that there can be different mentoring approaches (Hennissen et al., 2008). For example, Richter et al. (2013) found that mentoring based on the constructivist approach (which in essence characterizes SDT), as opposed to mentoring based on transfer of knowledge, promotes professional efficacy, teacher enthusiasm, job satisfaction, and reduced emotional exhaustion among new teachers. Similar results have been obtained by Burger et al. (2021). These studies reinforce the findings of the present study regarding the positive effects of mentoring that supports the teachers' needs.

The present study's findings join those of previous studies indicating the importance of support systems for BTs, and the range of contextual factors that impact their integration into teaching (Kutsyuruba et al., 2017; Mcdossi \& Kaplan, 2019; Thomas et al., 2019). A review of new-teacher absorption programs (Kutsyuruba et al., 2017) found that new teachers thrive in schools whose organizational culture is typified by collaboration, and which enable sharing of ideas, materials, and difficulties. It is important for the new teachers' teaching philosophy to be suited to the school culture. Additional factors are fellow teachers who provide social support, and mentors who aid the new teachers' acquaintance with the organizational culture. Thomas et al. (2019) found that collegial, social, and emotional support affects job satisfaction and intrinsic motivation for teaching. Eyal and Roth (2011) found that an autonomy-supportive management style led to autonomous motivation, and reduced burnout among teachers These findings are consistent with those of the present study.

The present study's findings are consistent with studies indicating the positive contribution of new-teacher support workshops (Fresko \& Nasser-Abu Alhija, 2015; Ingersoll \& Strong, 2011; Kaplan et al., 2016). In a recent study of interns and new teachers that supports these findings, Mcdossi \& Kaplan (2019) found three main teacher support systems: support from the school, support from the mentor, and support from the college workshop facilitator. Each of these systems uniquely contributed to teachers' sense of relatedness and sense of competence, which in turn positively predicted autonomous motivation for teaching, and negatively predicted sense of burnout. The findings indicate the importance of incorporating a number of support systems in new-teacher absorption programs.

Studies demonstrate the applicability of SDT in intervention studies designed to foster schools as optimal environments for student learning and development (Su \& Reeve, 2011; Assor et al., 2018), and indicate the effectiveness of intervention programs that focus on autonomy-supportive teaching (Perlman, 2015; Reeve et al., 2004). A review of the literature reveals that studies on school intervention programs, such as the present study, are few and far between. The paucity of research on interventions focusing on supporting the needs of BTs indicates the importance of the present study.

\subsection{Contending with Difficulties or Experiencing Growth?}

The literature in Israel and the world presents a wealth of studies describing the 
difficulties encountered by BTs (Kaplan, 2021a). The findings of the present study paint a completely different picture. Although the teachers report that working at the school creates an experience of overload and stress, they also experienced support from the principal and various administrators, experienced teachers, mentors, fellow BTs, and the workshop facilitator. In turn, this support creates an experience of need satisfaction.

The intervention program discussed in this article is based on a paradigm of health and growth, which characterizes SDT (Deci \& Vansteenkiste, 2004). This paradigm views the transition from the training stage to the teaching stage as a normative developmental transition, which can invite processes of identity construction and thriving. La Guardia (2009) argues that states of change, e.g., a career change or new workplace, can promote identity construction processes entailing reintegration of values, aims, roles, relationships, and demands. For these processes to take place, a need-supportive environment is necessary, as found in the present study. The motivational processes that develop as a result of need support can serve as inner resilience resources that can moderate the negative effects that may emerge in situations of crisis or difficulty, which BTs are likely to encounter following the transition to the world of work (Vansteenkiste \& Ryan, 2013).

\subsection{Limitations and Future Directions}

The present study has a number of limitations. First, it was primarily based on semi-structured interviews conducted at the end of the year, in which the interviewees were asked to recall and describe their experiences throughout the entire school year. Moreover, the study is largely based on the reports of participants in the program, and to a lesser degree on observations. Future studies should also employ quantitative or mixed method research designs, which can enrich and reinforce the findings.

Additionally, the study is about one school. It would be beneficial to continue accompanying additional schools that implement the intervention program described in the present article, and examining whether these findings recur. In this respect, it is important to remember that the nature or the characteristics of a PLC can be affected by contextual, cultural factors (Turner et al., 2018). Thus, it is recommended to examine schools from various cultures, regions, and contexts.

\section{Conclusion}

The present study is a case study that facilitates learning about one model of a PLC of teachers during their induction period. The research literature indicates the multiple difficulties encountered by BTs. The present study introduces a unique support system, called Multi-Players Induction Teams, comprising interns, new teachers, and mentors, as well as school administrators and policymakers. This is a unique SDT-based project whose results and outcomes are de- 
scribed in the article.

The article presented the outlook and principles underpinning the intervention program, and ways to support BTs. The program indicates the importance of a need-supportive environment for BTs and teacher-mentors alike. The findings provide readers with real-life examples from which they can continue to learn about the importance of the intervention program and ways to implement it.

\section{Acknowledgements}

The program was developed and implemented as part of the international Proteach Program (Erasmus+ Project, European Union).

\section{Conflicts of Interest}

The authors declare no conflicts of interest regarding the publication of this paper.

\section{References}

Aarts, R., Kools, Q., \& Schildwacht, R. (2019). Providing a Good Start. Concerns of Beginning Secondary School Teachers and Support Provided. European Journal of Teacher Education, 43, 277-295. https://doi.org/10.1080/02619768.2019.1693992

Abu Ras, R. (2010). Induction Program for Beginning Teachers in Bedouin Schools in the South of Israel. Dapim, 50, 160-185. (In Hebrew)

Aelterman, N., Vansteenkiste, M., Keer, H. V., \& Haerens, L. (2016). Changing Teachers' Beliefs Regarding Autonomy Support and Structure: The Role of Experienced Psychological Need Satisfaction in Teacher Training. Psychology of Sport and Exercise, 23, 64-72. https://doi.org/10.1016/j.psychsport.2015.10.007

Alegado, P. J. E., \& Soe, H. Y. (2021). A Comparative Analysis of the Effects of Mentoring among Participating Countries in 2013 and 2018 Teaching and Learning International Survey (TALIS). International Journal of Research Studies in Education, 10, 45-59. https://doi.org/10.5861/ijrse.2021.5077

Antinluoma, M., Ilomäki, L., \& Toom, A. (2021). Practices of Professional Learning Communities. Frontiers in Education, 6, Article ID: 617613. https://doi.org/10.3389/feduc.2021.617613

Argyris, C., \& Schön, D. A. (1978). Organizational Learning: A Theory of Action Perspective. Addison-Wesley.

Assor, A., Feinberg, O., Kanat-Maymon, Y., \& Kaplan, H. (2018). Reducing Violence in Non-Controlling Ways: A Change Program Based on Self-Determination Theory. The Journal of Experimental Education, 86, 195-213. https://doi.org/10.1080/00220973.2016.1277336

Assor, A., Kaplan, H., \& Roth, G. (2002). Choice Is Good, but Relevance Is Excellent: Autonomy Enhancing and Suppressing Teaching Behaviors Predicting Students' Engagement in Schoolwork. British Journal of Educational Psychology, 27, 261-278. https://doi.org/10.1348/000709902158883

Baker-Doyle, K. J. (2011). The Networked Teacher: How New Teachers Build Social Networks for Professional Support. Teachers College Press.

Beachboard, M. R., Beachboard, J. C., Li, W., \& Adikson, S. R. (2011). Cohorts and Rela- 
tedness: Self-Determination Theory as an Explanation of How Learning Communities Affect Educational Outcomes. Research in Higher Education, 52, 853-874. https://doi.org/10.1007/s11162-011-9221-8

Boe, E. E., Cook, L. H., \& Sunderland, R. J. (2008). Teacher Turnover: Examining Exit Attrition, Teaching Area Transfer, and School Migration. Exceptional Children, 75, 7-31. https://doi.org/10.1177/001440290807500101

Burger, J., Bellhäuser, H., \& Imhof, M. (2021). Mentoring Styles and Novice Teachers' Well-Being: The Role of Basic Need Satisfaction. Teaching and Teacher Education, 103, Article ID: 103345. https://doi.org/10.1016/j.tate.2021.103345

Central Bureau of Statistics, Israel (CBS) (2019). Internal Mobility and Leaving the System among Teaching Staff, 2000-2018. Internal Mobility and Leaving the System among Teaching Staff, 2000-2018. https://www.cbs.gov.il/EN/pages/default.aspx

Collie, R. J., \& Perry, N. E. (2019). Cultivating Teacher Thriving through Social-Emotional Competence and Its Development. The Australian Educational Researcher, 46, 699-714. https://doi.org/10.1007/s13384-019-00342-2

Creswell, J. W., \& Poth, C. N. (2018). Qualitative Inquiry Research Design: Choosing among Five Approaches. Sage Publishing.

De Neve, D., \& Devos, G. (2017). Psychological States and Working Conditions Buffer Beginning Teachers' Intention to Leave the Job. European Journal of Teacher Education, 40, 6-27. https://doi.org/10.1080/02619768.2016.1246530

Deci, E. L., \& Ryan, R. M. (2000). The "What" and "Why" of Goal Pursuits: Human Needs and the Self-Determination of Behavior. Psychological Inquiry, 11, 227-268. https://doi.org/10.1207/S15327965PLI1104 01

Deci, E. L., \& Vansteenkiste, M. (2004). Self-Determination Theory and Basic Need Satisfaction: Understanding Human Development in Positive Psychology. Ricerche di Psicologia, 27, 23-40.

Eyal, O., \& Roth, G. (2011). Leadership and Teachers' Motivation: Self-Determination Theory Analysis. Journal of Educational Administration, 49, 256-275. https://doi.org/10.1108/09578231111129055

Fernet, C., Senécal, C., Guay, F., Marsh, H., \& Dowson, M. (2008). The Work Tasks Motivation Scale for Teachers (WTMST). Journal of Career Assessment, 16, 256-279. https://doi.org/10.1177/1069072707305764

Fernet, C., Trépanier, S. G., Austin, S., \& Levesque-Côté, J. (2016). Committed, Inspiring, and Healthy Teachers: How Do School Environment and Motivational Factors Facilitate Optimal Functioning at Career Start? Teaching and Teacher Education, 59, 481-491. https://doi.org/10.1016/j.tate.2016.07.019

Flores, M. A. (2017). The Complexities and Challenges of Be(com)ing a Teacher and a Teacher Educator. European Journal of Teacher Education, 40, 2-5. https://doi.org/10.1080/02619768.2017.1280238

Ford, A. (2017). Who Mentors the Mentors? Curriculum and Development for Mentors of New Teachers in Israel. Doctoral Dissertation, Ontario Institute for Studies in Education, University of Toronto.

Frank, K., Kim, J., Salloum, S., Bieda, K., \& Youngs, P. (2020). From Interpretation to Instructional Practice: A Network Study of Early Career Teachers' Sensemaking in the Era of Accountability Pressures and Common Core State Standards. American Educational Research Journal, 57, 2293-2338. https://doi.org/10.3102/0002831220911065

Fresko, B., \& Nasser-Abu Alhija, F. (2015). Induction Seminars as Professional Learning Communities for Beginning Teachers. Asia-Pacific Journal of Teacher Education, 43, 
36-48. https://doi.org/10.1080/1359866X.2014.928267

Fullan, M. (2007). The Meaning of Educational Change (4th ed). Teachers College Press.

Hennissen, P., Crashborn, F., Brouwer, N., Korthagen, F., \& Bergen, T. (2008). Mapping Mentor Teachers' Roles in Mentoring Dialogues. Educational Research Review, 3, 168-186. https://doi.org/10.1016/j.edurev.2008.01.001

Herrington, A., Herrington, J., Kervin, L., \& Ferry, B. (2006). The Design of an Online Community of Practice for Beginning Teachers. Contemporary Issues in Technology and Teacher Education, 6, 120-132.

Howe, E. R. (2006). Exemplary Teacher Induction: An International Review. Educational Philosophy and Theory, 38, 287-297. https://doi.org/10.1111/j.1469-5812.2006.00195.x

Hsieh, H. F., \& Shannon, S. E. (2005). Three Approaches to Qualitative Content Analysis. Qualitative Health Research, 15, 1277-1288.

https://journals.sagepub.com/doi/pdf/10.1177/1049732305276687

https://doi.org/10.1177/1049732305276687

Imanuel, D. (2019). Teacher Incubators during the Induction Stage. Ministry of Education, Educational Workers Administration, Division of Internship and Teacher Induction. (In Hebrew)

In de Wal, J. J., den Brok, P. J., Hooijer, J. G., Martens, R. L., \& van den Beemt, A. (2014). Teachers' Engagement in Professional Learning: Exploring Motivational Profiles. Learning and Individual Differences, 36, 27-36.

https://doi.org/10.1016/j.lindif.2014.08.001

Ingersoll, R. M., \& Strong, M. (2011). The Impact of Induction and Mentoring Programs on Beginning Teachers. Review of Educational Research, 81, 201-233.

https://doi.org/10.3102/0034654311403323

Kacen, L., \& Krumer-Nevo, M. (2010). Introduction to Qualitative Data Analysis. In L. Kacen, \& M. Krumer-Nevo (Eds.), Qualitative Data Analysis (pp. 1-16). Ben-Gurion University Press. (In Hebrew)

Kaplan, H. (2018). Teachers' Autonomy Support, Autonomy Suppression and Conditional Negative Regard as Predictors of Optimal Learning Experience among High-Achieving Bedouin Students. Social Psychology of Education, 21, 223-255. https://doi.org/10.1007/s11218-017-9405-y

Kaplan, H. (2021a). Suppression of Psychological Needs among Beginning Teachers: A Self-Determination Theory Perspective on the Induction Process in Bedouin Schools. Frontiers in Psychology, 12, Article ID: 621984. https://doi.org/10.3389/fpsyg.2021.621984

Kaplan, H. (2021b). Promoting Optimal Induction to Beginning Teachers Using Self-Determination Theory. Sage Open, 11. https://doi.org/10.1177/21582440211015680

Kaplan, H., \& Assor, A. (2012). Enhancing Autonomy-Supportive I-Thou Dialogue in Schools: Conceptualization and Socio-Emotional Effects of an Intervention Program. Social Psychology of Education, 15, 251-269 https://doi.org/10.1007/s11218-012-9178-2

Kaplan, H., \& Israel, V. (2020). SDT/Autonomy-Based Mentoring: The ABC Mentoring Model (Autonomy, Belongingness, Competence, Community). Work Package 1, Erasmus+ Promentors Project, Growth Resources, Kaye Induction Unit.

Kaplan, H., \& Madjar, N. (2017). The Motivational Outcomes of Psychological Need-Support among Pre-Service Teachers: Multicultural and Self-Determination Theory Perspectives. Frontiers in Education, 2, 42.

https://doi.org/10.3389/feduc.2017.00042 
Kaplan, H., Glassner, A., \& Ades, S. (2016). Support for Basic Psychological Needs and the Exploration of Exploratory Processes in Novice Teachers as a Resource for the Construction of a Professional Identity. Dapim, 63, 130-165. MOFET Institute. (In Hebrew)

Klassen, R. M., Perry, N. E., \& Frenzel, A. C. (2012). Teachers' Relatedness with Students: An Underemphasized Component of Teachers' Basic Psychological Needs. Journal of Educational Psychology, 104, 150-165. https://doi.org/10.1037/a0026253

Kutsyuruba, B., Walker, K. D., \& Godden, L. (2017). Creating Supportive School Cultures for Beginning Teachers: Mitigating the Cultural Contextual Factors. The International Journal of Educational Organization and Leadership, 24, 1-18.

La Guardia, J. G. (2009). Developing Who I Am: A Self-Determination Theory Approach to the Establishment of Healthy Identities. Educational Psychologist, 44, 90-104.

https://doi.org/10.1080/00461520902832350

Lazovsky, R., \& Zeiger, T. (2004). Teaching Internship_Evaluation by Student Teachers in Different Training Tracks of the Contribution of the Mentor, the Internship Workshop, and the Program as a Whole. Dappim, 37, 65-95. (In Hebrew)

Lomos, C., Hofman, R. H., \& Bosker, R. J. (2011). Professional Communities and Student Achievement-A Meta-Analysis. School Effectiveness and School Improvement, 22, 121-148. https://doi.org/10.1080/09243453.2010.550467

Mcdossi, O., \& Kaplan, H. (2019). The Contribution of Supporting System Frameworks for Beginning Teachers' Success: The Proteach Model. Paper presented at the 7th International Conference on Teacher Education: The Story of Innovation in Teacher Education. MOFET Institute, Tel Aviv, Israel, 24-26 June 2019.

Nie, Y., Chua, B. L., Yeung, A. S., Ryan, R. M., \& Chan, W. Y. (2014). The Importance of Autonomy Support and the Mediating Role of Work Motivation for Well-Being: Testing Self-Determination Theory in a Chinese Work Organization. International Journal of Psychology, 50, 245-255. https://doi.org/10.1002/ijop.12110

Oplatka, I. (2015). The Essentials of Educational Administration: Leadership and Management in the Educational Organization (3rd extended ed.). Pardes. (In Hebrew)

Owen, S. (2016) Professional Learning Communities: Building Skills, Reinvigorating the Passion, and Nurturing Teacher Wellbeing and "Flourishing" within Significantly Innovative Schooling Contexts. Educational Review, 68, 403-419. https://doi.org/10.1080/00131911.2015.1119101

Pelletier, L. G., Séguin-Lévesque, C., \& Legault, L. (2002). Pressure from Above and Pressure from Below as Determinants of Teachers' Motivation and Teaching Behavior. Journal of Educational Psychology, 94, 186-196.

https://doi.org/10.1037/0022-0663.94.1.186

Pennanen, M., Heikkinen, H. L., \& Tynjälä, P. (2017). Virtues of Mentors and Mentees in the Finnish Model of Teachers' Peer-Group Mentoring. Scandinavian Journal of Educational Research, 64, 355-371. https://doi.org/10.1080/00313831.2018.1554601

Perlman, D. (2015). Assisting Preservice Teachers toward More Motivationally Supportive Instruction. Journal of Teaching in Physical Education, 34, 119-130. https://doi.org/10.1123/jtpe.2013-0208

Pillen, M., Beijaard, D., \& den Brok, P. (2013). Tensions in Beginning Teachers' Professional Identity Development, Accompanying Feelings and Coping Strategies. European Journal of Teacher Education, 36, 240-260.

https://doi.org/10.1080/02619768.2012.696192

Qian, H., Youngs, P., \& Frank, K. (2013). Collective Responsibility for Learning: Effects on Interactions between Novice Teachers and Colleagues. Journal of Educational 
Change, 14, 445-464. https://doi.org/10.1007/s10833-013-9210-0

Reeve, J. (2006). Teachers as Facilitators: What Autonomy-Supportive Teachers Do and Why Their Students Benefit. Elementary School Journal, 106, 225-236. https://doi.org/10.1086/501484

Reeve, J., \& Assor, A. (2011). Do Social Institutions Necessarily Suppress Individuals' Need for Autonomy? The Possibility of Schools as Autonomy Promoting Contexts across the Globe. In V. I. Chirkov, R. M. Ryan, \& K. M. Sheldon (Eds.), Human Autonomy in Cross-Cultural Context: Perspectives on the Psychology of Agency, Freedom and Well-Being (pp. 111-132). Springer. https://doi.org/10.1007/978-90-481-9667-8 6

Reeve, J., \& Cheon, S. H. (2021). Autonomy-Supportive Teaching: Its Malleability, Benefits, and Potential to Improve Educational Practice. Educational Psychologist, 56, 54-77. https://doi.org/10.1080/00461520.2020.1862657

Reeve, J., Jang, H., Carrell, D., Jeon, S., \& Barch, J. (2004). Enhancing Students' Engagement by Increasing Teachers' Autonomy Support. Motivation and Emotion, 28, 147-169. https://doi.org/10.1023/B:MOEM.0000032312.95499.6f

Richter, D., Kunter, M., Lüdtke, O., Klusmann, U., Anders, Y., \& Baumert, J. (2013). How Different Mentoring Approaches Affect Beginning Teachers' Development in the First Years of Practice. Teaching and Teacher Education, 36, 166-177. https://doi.org/10.1016/j.tate.2013.07.012

Roth, G., Assor, A., Kanat-Maymon, Y., \& Kaplan, H. (2007). Autonomous Motivation for Teaching: How Self-Determined Teaching May Lead to Self-Determined Learning. Journal of Educational Psychology, 99, 761-774. https://doi.org/10.1037/0022-0663.99.4.761

Ryan, E., \& Deci, E. (2020). Intrinsic and Extrinsic Motivation from a Self-Determination Theory Perspective: Definitions, Theory, Practices, and Future Directions. Contemporary Educational Psychology, 61, Article ID: 101860. https://doi.org/10.1016/j.cedpsych.2020.101860

Ryan, R. M., \& Deci, E. L. (2017). Self-Determination Theory. Basic Psychological Needs in Motivation, Development, and Wellness. The Guilford Press. https://doi.org/10.1521/978.14625/28806

Ryan, R. M., Lynch, M. F., Vansteenkiste, M., Deci, E. L. (2011). Motivation and Autonomy in Counseling, Psychotherapy, and Behavior Change: A Look at Theory and Practice. The Counseling Psychologist, 39, 193-260.

https://doi.org/10.1177/0011000009359313

Schmidt, J., Klusmann, U., Lüdtke, O., Möller, J., \& Kunter, M. (2017). What Makes Good and Bad Days for Beginning Teachers? A Diary Study on Daily Uplifts and Hassles. Contemporary Educational Psychology, 48, 85-97. https://doi.org/10.1016/j.cedpsych.2016.09.004

Sela, O., \& Harel, M. (2018). You Have to Prove Yourself, Initiate Projects, Be Active: The Role of Novice Teachers in Their Own Induction Process. Professional Development in Education, 45, 190-204. https://doi.org/10.1080/19415257.2018.1441173

Shkedi, A. (2003). Words That Try to Touch: Qualitative Research-Theory and Application. Ramot. (In Hebrew)

Shkedi, A. (2014). The Meaning behind the Words: Methodologies of Qualitative Research-Theory and Practice. Ramot. (In Hebrew)

Sperling, D. (2015). Teacher Dropout around the World: Information Survey. MOFET Institute. (In Hebrew) 
Stoll, L., Bolam, R., Mcmahon, A., Wallace, M., \& Thomas, S. (2006). Professional Learning Communities: A Review of the Literature. Journal of Educational Change, 7, 221-258. https://doi.org/10.1007/s10833-006-0001-8

Su, Y. L., \& Reeve, J. (2011). A Meta-Analysis of the Effectiveness of Intervention Programs Designed to Support Autonomy. Educational Psychology Review, 23, 159-188. https://doi.org/10.1007/s10648-010-9142-7

Teasly, M. L. (2017). Organizational Culture and Schools: A Call for Leadership and Collaboration. Children and Schools, 39, 3-6. https://doi.org/10.1093/cs/cdw048

Thomas, T., Tuytens, M., Moolenaar N., Devos, G., Kelchtermans, G., \& Vanderlinde, R. (2019). Teachers' First Year in the Profession: The Power of High-Quality Support. Teachers \& Teaching, 25, 166-188. https://doi.org/10.1080/13540602.2018.1562440

Turner, J. C., Christensen, A., Kackar-Cam, H. Z., Fulmer, S. M., \& Trucano, M. (2018). The Development of Professional Learning Communities and Their Teacher Leaders: An Activity Systems Analysis. Journal of the Learning Sciences, 27, 49-88. https://doi.org/10.1080/10508406.2017.1381962

Ulvik, M., \& Langørgen, K. (2012). What Can Experienced Teachers Learn from Newcomers? Newly Qualified Teachers as a Resource in Schools. Teachers and Teaching, 18, 43-57. https://doi.org/10.1080/13540602.2011.622553

Van den Berghe, L., Soenens, B., Aelterman, N., Cardon, G., Tallir, I. B., \& Haerens, L. (2014). Within-Person Profiles of Teachers' Motivation to Teach: Associations with Need Satisfaction at Work, Need-Supportive Teaching, and Burnout. Psychology of Sport and Exercise, 15, 407-417. https://doi.org/10.1016/j.psychsport.2014.04.001

Vansteenkiste, M., \& Ryan, R. M. (2013). On Psychological Growth and Vulnerability: Basic Psychological Need Satisfaction and Need Frustration as a Unifying Principle. Journal of Psychotherapy Integration, 23, 263-280. https://doi.org/10.1037/a0032359

Yossifon, M. (2016). Case Study. In N. Tsabar-Ben Yehoshua (Ed.), Traditions and Genres in Qualitative Research: Philosophies, Strategies and Advanced Tools (pp. 179-216). MOFET Institute. (In Hebrew) 